\title{
ARTÍCULOS
}

\section{AGENTES E INTELIGENCIA EN LA FRONTERA DE LA LUISIANA A FINALES DEL SIGLO XVIII: LA PRESIÓN DE LOS ESTADOS UNIDOS.}

\author{
Antoni Picazo Muntaner \\ Universitat de les Illes Balears \\ a.picazo@uib.es
}

Resumen: A lo largo del siglo XVII y XVIII los conflictos y los choques entre distintas potencias en los territorios de frontera de América no dejaron de crecer. Y cada uno de los participantes en esa carrera colonial buscó aliados nativos para utilizarlos como unidades militares de apoyo. Pero las distintas naciones europeas también necesitaron información para sus posibles actuaciones, y desinformación para sus rivales. Entre los ejemplos más evidentes de esa dinámica se halla el extenso territorio de Luisiana.

Palabras clave: Luisiana, nativos, España, Estados Unidos, frontera, conflicto, siglo XVIII.

Tittle: AGENTS AND INTELLIGENCE IN THE BORDER OF LUISIANA AT THE END OF THE $18^{\text {TH }}$ CENTURY: THE PRESSUERE OF THE UNITED STATES.

Abstract: Throughout the $17^{\text {th }}$ and $18^{\text {th }}$ centuries, conflicts and clashes between different powers in the border territories of America did not stop growing. And each of the participants in that colonial race sought native allies to use them as military support units. But the different European nations also needed information for their possible actions, and misinformation for their rivals. Among the most obvious examples of this dynamic is the vast territory of Louisiana.

Keywords: Louisiana, natives, Spain, United States, border, conflict, $18^{\text {th }}$ century.

\section{La Luisiana: un estado de la cuestión}

Mucho se ha escrito sobre la Luisiana desde ambos lados del Atlántico, tanto desde los Estados Unidos y México, como de la misma España. Estudios que han fijado su atención en líneas investigadoras diferentes, comenzando por los aspectos político-administrativos, pasando por los poblacionales, comerciales y religiosos, hasta los sociales.

Entre las investigaciones que analizan la población de Luisiana destacaríamos los de Antonio Acosta (con la aportación de unos datos muy fiables); las de José Montero (obra que fue traducida en Estados Unidos y que evidencia la influencia

Cómo citar este artículo: PICAZO MUNTANER, Antoni. Agentes e inteligencia en la frontera de la Luisiana a finales del siglo XVIII: la presión de los Estados Unidos. Naveg@mérica. Revista electrónica editada por la Asociación Española de Americanistas [en línea]. 2020, n. 24. Disponible en: <http://revistas.um.es/navegamerica>. [Consulta: Fecha de consulta]. ISSN 1989-211X. 
española en la formación urbana), o Luis Arnal (que percibió el problema en su conjunto.

Entre los mayores especialistas del conocimiento de la historia de la Luisiana, en todos sus aspectos, desde los religiosos a los defensivos, pasando por los políticos o económicos, destaca la figura de José Antonio Armillas'. En cambio, en el análisis de la estructura político-administrativa sobresalen diferentes autores, entre ellos V. Rodríguez Casado, S. Hilton, Gilbert Din, J. B. Amores, G. Segura o Th. M. Fiehrer ${ }^{2}$, entre otros muchos de imposible cita. De todos ellos quisiéramos destacar el extraordinario análisis que realizó S. Hilton en su artículo sobre la movilidad de los colonos norteamericanos, y el peligro que ello reportaba a la administración española. Por otro lado, y profundizando en las relaciones entre los nativos y las distintas potencias que jalonaban las fronteras reseñaríamos los trabajos de $\mathrm{A}$. Levaggi, que dejó meridianamente claro el peligro que representaba para Nueva España la rápida expansión hacia el sur que tenían los Estados Unidos y el intento de diseñar un nuevo tipo de política; Frank Defina, que subrayó el papel de los mestizos o C. González López-Briones ${ }^{3}$, que con un magnífico artículo expuso -muy certeramente- los impactos que la presencia europea provocó en las naciones indias del valle de Mississippi, en especial el comercio; o el trabajo de Juan José Andreu Ocáriz ${ }^{4}$.

\footnotetext{
${ }^{1}$ Entre sus obras, cabría destacar: ARMILLAS VICENTE, José Antonio. El Mississippi, frontera de España. España y los Estados Unidos ante el tratado de San Lorenzo. Zaragoza: Institución "Fernando el Católico" (C.S.I.C.); Departamento de Historia Moderna,1977; ARMILLAS VICENTE, José Antonio. Orígenes de la "Cuestión del Mississippi". Las Naciones Indias de Chactas y Chicasas y el dominio español de las dos orillas del río. En: El Mundo hispánico en el siglo de las Luces. Actas del Coloquio Internacional "Unidad y diversidad en el mundo hispánico del siglo XVIII". Madrid: Sociedad Española de Estudios del siglo XVIII-Editorial Complutense, pp. 401-416; ARMILLAS VICENTE, José Antonio. Las relaciones diplomáticas entre España y los Estados Unidos desde el Tratado de San Lorenzo (1795) al de Adams-Onís (1819). Revista de Historia Militar. 2007, no extra 2, pp. 159-200.

HILTON, Sylvia L. Movilidad y expansión en la construcción política de los Estados Unidos: "estos errantes colonos" en las fronteras españolas del Misisipí (1776-1803). Revista complutense de historia de América. 2002, vol. 28, pp. 63-96; DINN, Gilbert. La defensa de la Luisiana Española en sus primeros años. Madrid: Servicio Histórico Militar, 1978; AMORES, Juan Bosco. La Capitanía General de Cuba y la defensa de Luisiana y Florida ante el expansionismo norteamericano (17831789). En: ARMILLAS, J. A. (ed.). Actas del VII Congreso Internacional de Historia de América. Zaragoza, 1998, pp. 787-797; SEGURA, Germán. Organización militar de la Luisiana española durante la revolución americana (siglo XVIII). En: MARTÍNEZ RUIZ, Enrique [et al.] (eds.). La organización de los ejércitos. Madrid: Ministerio de Defensa, 2016, pp. 913-957; FIEHRER, Thomas. The baron de Carondelet as agent of Bourbon reform: a study of spanish colonial administration in the years of the French revolution. N. O.: Tulane University, 1977.

${ }^{3}$ LEVAGGI, Abelardo. Aplicación de la política española de tratados a los indios de la Nueva España y sus confines: El caso de la Luisiana y las Floridas (1791-1798). Anuario Mexicano de Historia del Derecho. 1998, n. 10, pp. 449-483; DEFINA, Frank. Mestizos y blancos en la política india de la Luisiana y la Florida del siglo XVIII. Revista de Indias. 1966, pp. 59-77; GONZÁLEZ LÓPEZBRIONES, Carmen. Reacciones diferentes ante una Política Similar: Los indios Osages y los Quapaws ante la política comercial franco-española en la Luisiana durante el siglo XVIII. Anales del Museo de América. 1995, pp. 119-130.

4 ANDREU OCÁRIZ, Juan José. Penetración española entre los indios osages. Zaragoza: Universidad de Zaragoza, 1964.
} 


\section{La frontera: del mito a la geoestrategia}

A pesar de las definiciones de frontera que aparecen en los distintos diccionarios, que la reflejan como un elemento separador de territorios, nosotros quisiéramos hacer una reflexión desde otra vertiente, la que alude a la "separación del otro", la ideológica. No sería más que aquella idea de flujo cultural, en todas sus

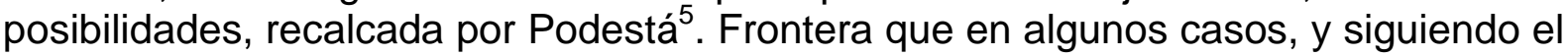
mismo autor, puede ser "caliente". Una concepción ésta que a menudo implicaba, secundando a Hobbes y su nuevo concepto de alteridad, el temor, el miedo. Pero que en otros también abrían la posibilidad de la "riqueza rápida", uno de los factores que posibilitó más exploraciones en todo el septentrión americano. Es decir, las mismas líneas teóricas que fueron trazadas por Miroslav Hroch ${ }^{6}$, centrándonos en la "diferencia". De ahí que, evidentemente, la frontera, además de ese aspecto cultural y económico, se convirtiera también en una zona de vigilancia continua, de combate, de aniquilación del "otro". Una frontera, la del Mississippi, evidentemente porosa donde las hubiera ${ }^{7}$.

La frontera, los spanish borderlands ${ }^{8}$, cuyo trabajo pionero de Herbert E. Bolton se ha convertido en todo un clásico, fue un vasto territorio que abarcó desde Nootka, trazando una diagonal que pasaba por el Nuevo México, hasta la misma Florida. Sin embargo, la presencia hispánica en esa vasta región no fue completa, ni uniforme. Los grandes vacíos completamente despoblados, a no ser por la presencia indígena, podían cuestionar la legitimidad de esa posesión. Cuestión que fue rápidamente disputada por diferentes potencias. Ciertamente, ante la donación papal, anteponían el concepto emanado del de Justiniano de "Terra Nullius", perfectamente analizado por Simsarian". En esa tesitura, las autoridades españolas fijaron su atención en crear "antemurales" para proteger el virreinato. Antemural que primero pasó por Texas para luego extenderse hasta California. Sin embargo, desde los inicios de la colonización de Nueva España, hasta bien entrado el siglo XVIII, las expediciones que se adentraron en esos parajes se fueron repitiendo de forma escalonada. Unas para buscar mitos y quimeras, tales como la Ciudad del Rey Coronado, las Siete Ciudades de Cíbola, o la no menos mítica Quivira ${ }^{10}$. Esos espacios imaginarios

\footnotetext{
${ }^{5}$ PODESTÁ ARZUBIAGA, Juan. Regiones fronterizas y flujos culturales: La peruanidad en una región chilena. Universum (Talca). 2011, vol. 26, n. 1, pp. 123-137.

${ }^{6} \mathrm{HROCH}$, Miroslav. La construcción de la identidad nacional: del grupo étnico a la nación moderna. Revista de Occidente. 1999, n. 161, pp. 1-9.

7 GALAN, Francis X. Last Soldiers, First Pioners; The Los Adaes Border Community on the Louisiana-Texas frontier, 1721-1729. Southern Methodist University, 2006, lo refleja del siguiente modo "From the east came Mississippi-based Natchez and Choctaw Indians in response to imperial wars fought among Spain, France, and England with their southeastern Indians allies", p. 8.

${ }^{8}$ BOLTON, Hebert E. The Spanish Borderlands: a Chronicle of old Florida and the Southwest. New Haven: Yale University Press, 1921; WORCESTER, Donald E. The Significance of the Spanish Borderlands to the United States. The Western Historical Quarterly. 1976, n. 7-1, pp. 5-18; WEBER, David J. The Spanish Borderlands, Historiography Redux. The History Teacher. 2005, n. 39-1, pp. 4356.

${ }^{9}$ SIMSARIAN, James. The Acquisition of Legal Title to Terra Nullius. Political Science Quarterly. 1938, n. 53-1, pp. 111-128.

${ }^{10}$ PICAZO, Antoni. La búsqueda de la Quivira en Texas: Fray Hidalgo y el Marqués de Aguayo. Anales del Museo de América. 2000, n. 8, pp. 287-292. Vid. También: PICAZO, Antoni. L'espai imaginari. La geografia fantàstica en la colonització d'Amèrica del nord. [El espacio imaginario. La
} 
jalonaron todos los mapas de la época, hasta bien entrado el siglo XIX, y funcionaron como verdaderos polos de atracción no solo para los españoles, sino que también lo hicieron para varios aventureros de todas las potencias europeas del momento. En cierta forma, la aparición de esas quimeras en numerosas obras cartográficas posibilitó una verdadera "concreción de la fantasía", pues todas ellas aparecían perfectamente localizadas. Otras, en cambio, buscaron la rentabilidad económica para sus promotores, sea para la explotación minera o ganadera, sea para el comercio de pieles. Esa vastedad, incontrolable a todas luces, provocó que se realizaran diferentes ordenanzas para su protección, como la de los presidios, o incluso una subdivisión administrativa, la Comandancia General de las Provincias Internas ${ }^{11}$, creada en 1776. Esta abarcaba todo el norte de Nueva España, concretamente aquellos territorios que se habían agregado en las últimas décadas. Esta nueva comandancia tenía un claro objetivo: centralizar la defensa para evitar una penetración de otras potencias como Rusia, Francia, Gran Bretaña o, posteriormente, los Estados Unidos.

Los bruscos cambios que vivió Europa en el siglo XVIII, con una coyuntura internacional marcada por el belicismo entre las diferentes potencias, hicieron que las autoridades variasen toda la estructura defensiva del norte de Nueva España. Para ello se elaboró un nuevo modelo, lo suficientemente efectivo, para frenar primero a los franceses y británicos; posteriormente sería utilizado para intentar paralizar a los norteamericanos. En la segunda mitad del siglo XVIII la zona había conocido un notable auge económico, derivado de la nueva política de los Borbones. $\mathrm{El}$ incremento de las cabezas de ganado ${ }^{12}$, el rápido despegue de la minería, que convertirían a Nueva España en la "perla de la Corona", y el desarrollo de la agricultura preveían un futuro más que próspero, y con ello un traspaso de rentas a la Hacienda Pública mucho más importantes. Esa boyante situación económica podría peligrar si algunas potencias enemigas llevaban a cabo viejos planes de ocupación de la zona minera, pero también si los hostiles indios del norte provocaban un parón productivo con el aislamiento de algunas regiones vitales ${ }^{13}$,

geografía fantástica en la colonización de América del norte]. Palma: El Tall, 2003; PICAZO MUNTANER, Antoni. Notas para una contribución a la concepción espacial y geografía mental de los comerciantes europeos en la Edad Media e inicios de la Moderna. Arquipélago. Revista da Universidade dos Açores. 2002, pp. 435-442; PICAZO, Antonio. Las utopías en la cartografía. En: Política y cultura en la época moderna: cambios dinásticos, milenarismos, mesianismos y utopías. Universidad de Alcalá: Servicio de Publicaciones, 2004, pp. 671-680.

${ }_{11}$ VELÁZQUEZ, María del Carmen. La comandancia general de las Provincias Internas. Historia mexicana. 1977, n. 27-2, pp. 163-176.

${ }^{12}$ TEJA, Jesús F. de la y CASTELLANOS, Armando. Sobrevivencia económica en la frontera de Texas: los ranchos ganaderos del siglo XVIII en San Antonio de Béxar. Historia mexicana. 1993, n. 42-4, pp. 837-865.

${ }^{13}$ En este aspecto cabe resaltar la contribución de LOCKWOOD, Frank G. The Apache Indians. University of Nebraska Press, 1987. En la parte final del capítulo dedicado a la relación entre los apaches y los españoles hace una breve, pero muy clarificadora, exposición de la situación en Texas y de las relaciones que se establecieron entre apaches, españoles y comanches, los juegos de alianzas y conveniencias y la preocupación de las autoridades virreinales para mantener la paz en el territorio. La obra de WORCESTER, Donald E. The Apaches: Eagles of the Southwest. University of Oklahoma Press, 1992, también realiza una valiosa síntesis de la época que trabajamos y en especial de las ideas de Gálvez para todas las POYO, Gerardo e HINOJOSA, Gilberto. Spanish Texas and Borderlands. Historiography in Transition, implications for U.S. History. The Journal of American History. 1988, vol. 75, n. 2, pp. 393-416. 
especialmente las argentíferas.

\section{Agentes e inteligencia}

Cierto que España siempre consideró al Caribe como un lago propio, un elemento sumamente estratégico que se debía controlar. Pero también es cierto que desde mediados del siglo XVII ello se tornó casi imposible. Primero por la presencia de ingleses y holandeses en algunas islas clave ${ }^{14}$. Segundo, por el propio desembarco inglés al sur de Yucatán (lo que obligó a una refortificación de la región). Finalmente, por la presencia francesa en Luisiana. Sin embargo, tras el fin del conflicto que enfrentó a Gran Bretaña, con Francia y España, la situación dio un nuevo vuelco. Primero por el dominio británico de Florida, y por la cesión (siempre condicionada) de Luisiana a España. Cesión esta que, aunque perseguía ser un antemural para la expansión anglo-norteamericana y para el control del golfo de México, se transmutó rápidamente en un verdadero quebradero de cabeza para las autoridades. Y ello por tres razones fundamentales.

La primera de ellas por el alto coste económico que suponía, con apenas un millar de soldados acantonados en diferentes fortificaciones ${ }^{15}$. Esa dotación era insuficiente frente al potencial que exhibían en los márgenes del río Ohio los Estados Unidos, que habían firmado una paz con los nativos, pero que mantenían en su ribera a unos cinco mil soldados ${ }^{16}$.

En segundo lugar, por la rápida expansión de colonos y la penetración comercial británica. Y, finalmente, por el intento de mantener a las distintas naciones indias en paz $^{17}$. Algunas de estas circunstancias se intentaron salvar mediante la diplomacia, 0 la compra de voluntades. Sería el caso, sin ir más lejos, de la paz forjada con los nativos. O con las repetidas cesiones de la corona española a los recién formados Estados Unidos, que siempre se presentaron para las autoridades hispanas como un peligro. Lógica que también compartían los indígenas, como lo resumen perfectamente $\mathrm{S}$. Hilton ${ }^{18}$. Pero para mantener a raya a los colonos, y acallar las

${ }^{14}$ MORALES, Arturo. Puerto Rico y la lucha por la hegemonía en el Caribe: colonialismo y contrabando, siglos XVI-XVIII. Río Piedras: UPR, 1995.

${ }_{15}$ AMORES, Juan Bosco. La Capitanía General de Cuba... Op. cit., p.796, explicita las distintas fortificaciones hispanas en Luisiana, sus hombres y oficiales, y la distancia hasta Nueva Orleans. Como el mismo indica, citando a Floridablanca, se trataba de crear "una barrera poblada de hombres que defiendan las introducciones y usurpaciones por aquellas partes", p. 787.

${ }^{16}$ AGI, Estado, 114, N1, "El gobernador de La Habana sobre la paz de los Estados Unidos con los Indios. 1793". Las cartas remitidas por las autoridades militares de Nueva Orleans, y del puesto avanzado de San Luis fueron reenviadas, a su vez, al Conde de Aranda.

${ }_{17}$ Sobre las relaciones hispano-nativas en Luisiana y la cuenca del Mississippi existe una abundante bibliografía, de la que destacaríamos, a HOLMES, J. Spanish Treaties with West Florida Indians, 1784-1802. Florida Historical Quarterly. 1969, n. 48-2, pp. 140-154; KINNAIRD, Lawrence. Spanish Treaties with Indian Tribes. Western Historical Quarterly. 1979, n. 10, pp. 39-48; DINN, Gilbert y NASATIR, Abraham. The Imperial Osages: A Study of Spanish Indian Diplomacy in the Mississippi Valley. Norman: University of Oklahoma Press, 1983.

${ }^{18}$ HILTON, Sylvia L. Movilidad y expansión... Op. cit., p. 92, "Los americanos», advertía Gayoso, «no han hecho más que introducirse en las tierras de los indios con pretexto de amistad, ofreciéndoles muchas cosas, y al cabo los han echado de sus mismas casas;... [los indios] recientemente tienen a la vista lo que están haciendo con sus vecinos hacia el Norte; que esto mismo es lo que sucederá dentro de poco a las naciones Cherokee, Chicasa, Chacta y Talapuche, si no se mantienen unidos 
pretensiones anglo-norteamericanas, las autoridades hispanas necesitaban, junto a las distintas naciones indias, información. $Y$ esta información procedía de dos fuentes fundamentales: Alexander McGuillivray ${ }^{19}$ y James Wilkinson ${ }^{20}$. El primero, un mestizo de la nación $\mathrm{Creek}^{21}$; el segundo, un oficial norteamericano.

Sin duda, podríamos calificar a McGuillivray como un agente al servicio de los españoles afincados en Luisiana. Sin embargo, no cabe ninguna duda que McGuillivray se centró en dos objetivos de carácter personal. El primero de ellos fue el de atender a las dos partes en conflicto, españoles-norteamericanos, pero con una única finalidad: salvaguardar la integridad de los $\mathrm{Creek}^{22}$. En cambio el segundo de sus objetivos se centró, principalmente, en la personalidad aventurera y tremendamente ambiciosa de McGuillivray el cual, a través de ese juego a dos bandas, logró acumular una verdadera fortuna con el comercio. En este sentido Thomas Jefferson había notificado a George Washington que este personaje controlaba el monopolio del contrato con toda la nación Creek y que, por tanto, les podía ser de gran utilidad. En esa línea, Thomas Jefferson comunicó a George Washington que McGuillivray, al que citó como coronel, junto a una serie de mercaderes, tenían el monopolio de comercio con los creek. ${ }^{23}$. En una coyuntura adversa, de temor español, ansiedad norteamericana y recelo nativo, McGuillivray supo alternar sabiamente las demandas y exigencias que le formulaban sendas potencias. En ese sentido, una carta reservada, dirigida a las autoridades de Madrid, reflejaba cual era la percepción y catadura moral que se tenían en Nueva Orleans de James Wilkinson ${ }^{24}$, al que calificaban como un brigadier que estuvo en el ejercito de los Estados Unidos en la guerra de independencia contra Gran Bretaña, católico, de ascendencia irlandesa, altanero, mentiroso, envidioso, que no era de fiar, y a los que se añadían todos los adjetivos despectivos posibles. Sin embargo, Wilkinson

como una sola nación y hermanos, apoyados de nuestra amistad y auxilio». En el informe del teniente Minor sobre su conversación con los Chactas, queda patente que los indígenas estaban perfectamente conscientes de su situación. Minor comunicó que el jefe Franchimastabe: «me contestó que tenía razones para creer que cuanto yo le había dicho era verdad, así que estaba determinado a vivir prevenido, pues no ignoraba el deseo que tenían los americanos de tomar las tierras de los indios y empobrecerlos siempre que lo podían ejecutar». Por eso no sorprendió nada cuando las tribus de la zona se opusieron a los trabajos de la comisión mixta hispano-norteamericana para la demarcación de límites, que se había acordado por el tratado de 1795 y que favorecía la expansión estadounidense".

19 Para la biografía de este personaje, vid. O'DONNELL, J. Alexander McGillivray: Training for Leadership, 1777-1783. The Georgia Historical Quarterly. 1965, n. 49, pp. 172-186.

${ }_{20}$ NARRETT, David E. Geopolitics and Intrigue: James Wilkinson, the Spanish Borderlands, and Mexican Independence. The William and Mary Quarterly. 2012, n. 69-1, pp. 101-146.

${ }^{21}$ BL, House of Lords, Calendar of State Papers Colonial America and West Indies, 44 (1738), pp. $94-$ 109. Evidencia que los españoles en 1719 se asentaron en los Apalaches, zona a la que califica de "deshabitada". Sin embargo, también se añade que los indios Uchee y Talapooza (que los ingleses denominaban Lower Creek) se habían quejado a las autoridades españolas que los ingleses estaban levantando un fuerte en sus tierras.

${ }^{22}$ ETHRIDGE, Robbie. Creek country: the Creek Indians and their world. Chapel Hill: UNC Press Books, 2004.

${ }^{23}$ LOC, George Washington Papers, Series 4, General Correspondence, MR 012, Thomas Jefferson to George Washington, Memorandum on Indian Trade, 29 de julio de 1790.

${ }^{24}$ LOC MSS 44693: Reel 102 George Washington Papers, Series 4, General Correspondence: James Wilkinson to Henry Knox, August 4, 1792. Le informa de dos inconvenientes, en primer lugar que hacía tiempo que no tenía noticias de sus confidentes, en segundo lugar que ante los ataques de los nativos había activado la milicia para luchar contra ellos. 
tenía una asignación anual de $2000 \operatorname{pesos}^{25}$ de la corona española como reconocimiento a los servicios que prestaba.

Con todo, a partir de 1790 la situación en Luisiana se volvió extremadamente difícil. La expansión de colonos de Georgia y Kentucky ${ }^{26}$ hacia el Mississippi era imparable, y los españoles temían un conflicto abierto con la joven república. Para contenerlos se arbitró una paz con los nativos que, aunque meramente testimonial, sirvió para atenuar los nervios que estaban aflorando a ambos lados de la frontera. En este sentido, el tratado de Nogales $^{27}$ de 1793 es un claro exponente de lo que acabamos de afirmar. Dicho documento fue firmado por Manuel Gayoso de Lemos, gobernador militar y político del distrito de Natchez, comisionado a tal efecto por el barón de Carondelet y, por la otra parte, por los representantes de las naciones Chicacha, Creek, Talapuche, Alibamones, Cherokee ${ }^{28}$ y Chakta ${ }^{29}$. Más que un tratado de paz lo fue de cooperación puesto que los nativos, en el artículo dos, demandaron la protección de la nación española y esta, en el artículo siguiente, se la concedió. El artículo cuarto es, tal vez, el más significativo por lo que se refiere al objetivo principal del mismo: los nativos formaron una alianza de defensa mutua contra "el común enemigo". Y una de las consecuencias fue la reclamación de un tratado de límites "... a fin de conservar cada una la pacífica posesión de sus tierra". Todo ello, pero, en un contexto de "compra de voluntades", dado que las autoridades españoles debían ofrecer, cada primavera, una serie de presentes a las distintas naciones. Regalos, que según Weber ${ }^{30}$, ascendían a una décima parte del monto total del coste de mantener el territorio. En última instancia, los nativos recurrieron a los españoles para salvaguardar las pretensiones norteamericanas sobre sus tierras:

"Los jefes Cherokis, actualmente en esta Ciudad, á cuya cabeza se halla Bloody Féllow, solicitan que la España restablezca dos fuertes antiguamente ocupados por los franceses; el de Tombecbé, situado en la nación Chacta, á los 32 grados y algunos minutos, que es á corta diferencia la misma latitud del fuerte de Nogales, del que, como de la Movila, dista ochenta leguas; y el de Muscle Shoals sobre el río Tenesy, ó Cheroki, en su misma nación, á los 34 grados y algunos minutos de la misma latitud, que dista de la orilla oriental del Misisipí unas treinta leguas, y del citado antiguo fuerte de Tombecbé unas veinte; por último, del Ohio, unas treinta y cuatro",31.

\footnotetext{
${ }^{25}$ AGS, Estado, SGU, Leg. 7245, 32, "Luisiana y Florida. Pobladores y comercio de indios", fol. 251.

${ }^{26}$ Sobre la tenencia de la tierra y los problemas derivados de ella, vid.: ARON, Stephen. Pioneers and Profiteers: Land Speculation and the Homestead Ethic in Frontier Kentucky. The Western Historical Quarterly. 1992, n.23-2, pp. 179-198.

${ }^{27}$ AGI, Documentos Reales, 7, "Tratado de Nogales, 1793".

${ }_{28}$ BOULWARE, Tyler. Deconstructing the Cherokee nation: town, region, and nation among eighteenth-century Cherokees. Gainesville: University Press of Florida, 2011.

29 JACOBS, Wilbur (ed.). The Appalachian Indian Frontier: The Edmond Atkin Report and Plan of 1755. Lincoln: University of Nebraska Press, 1967.

${ }^{30}$ WEBER, David J. Borbones y Bárbaros. Centro y periferia en la reformulación en la política de España hacia los indígenas no sometidos. Anuario Instituto Estudios Histórico Sociales. 1998, n. 13, pp. 147-171.

${ }^{31}$ AHN, Estado, Leg. 3898, "El barón de Carondelet al conde de Aranda, 1792".
} 


\section{Los Estados Unidos y los planes de colonización}

La presión de los Estados Unidos sobre Luisiana no cesó. Tal vez el más preocupante fue el plan diseñado en Georgia ${ }^{32}$ y Kentucky ${ }^{33}$ para el asentamiento en un territorio de unas 55.000 millas cuadradas de un gran número de colonos. A tal efecto se formalizó una compañía para ocupar un área muy extensa, perteneciente a varias naciones indias, en los márgenes del Mississippi. Compañía que estuvo impulsada por el sargento mayor Thomas Washington, sobrino del general Washington, y que estuvo creada por Alejandro Moultine, Guillemo Clay Sniper, Isaac Huge y John Clape. Asociación que instaba al coronel John Holder a ocupar toda esa región. Sin embargo, esta sociedad tuvo un enorme problema puesto que en 1797 las autoridades norteamericanas condenaron, presuntamente a la horca según una carta reservada, a Thomas Washington por falsificar una gran cantidad de moneda ${ }^{34}$.

La información secreta que recibieron los españoles fue muy elevada, especialmente del contenido de las cartas entre Augusta (Georgia) y Charlestón (Carolina), desde septiembre de 1789 hasta octubre de 1789, entre Thomas Washington, el coronel Holder y los comerciantes de esos dos estados ${ }^{35}$. En todo momento, entre algunos agentes y militares, como James Wilkinson ${ }^{36}$ y las españolas, Esteban Miró, la correspondía fluyó de forma constante. De este modo, El 30 de abril de 1790 Miró comunicó a Wilkinson ${ }^{37}$ que los territorios que se querían ocupar pertenecían a España, y que sería un acto de hostilidad. Miró subrayó que el tratado, al cual se remitían los norteamericanos, firmado con los nativos no era más que una quimera.

Ciertamente, la entrega de tierras por parte de los chactás en los pactos de 1786 no tenía ningún tipo de valor. Y ello por dos circunstancias bastante graves. En primer lugar, porque el nativo que firmó el tratado, Payemingo ${ }^{38}$, no tenía la autoridad suficiente, como le hicieron saber diferentes caudillos de los chactás ${ }^{39}$. En

\footnotetext{
${ }^{32}$ Los problemas en la frontera, entre colonos norteamericanos y tropas españolas no cesaban. En 1795 un grupo de unos 67 colonos penetraron en territorio de Luisiana, asaltando una pequeña fortificación española y capturando a un capitán junto a una pequeña compañía de 14 dragones. AGI, Estado, 5A, N13, "Excesos cometidos por vagabundos de Georgia, 1795".

${ }^{33}$ En 1797 el barón de Carondelet envió a Thomas Power a una misión secreta a Kentucky. Las intenciones eran las de potenciar la separación de ese estado del de la Unión, para que se integrasen a la corona española, con toda suerte de privilegios y mercedes. Sin embargo, dicho intento fue un fracaso estrepitoso. AGI, Estado, 1, N 68, "El gobernador de La Habana sobre el estado de Kentucky, 1797 ".

${ }^{34}$ AGS, SGU, Legajo 6928, 5, "Noticias del estado de Kentucky, 1797".

${ }^{35}$ AGS, Estado, SGU, Leg. 7245, 32, "Luisiana y Florida. Pobladores y comercio con indios, 1790".

${ }^{36}$ LOC, Andrew Jackon papers. Series correspondence and related.MSS 26532, vol. 28, hallamos una voluminosa correspondencia entre James Wilkinson y las autoridades norteamericanas.

${ }^{37}$ LOC, Andrew Jackon papers. Series correspondence and related, James Wilkinson to James Madison, 22 de febrero de 1787. Wilkinson recomendó la contratación de franceses asentados en los territorios puesto que conocían los idiomas y cultura nativas

${ }^{38}$ HOLMES, Jack. Louisiana in 1795 the Earliest Extant Issue of the "Moniteur De La Louisiane". Louisiana History. 1966, pp. 133-151. Holmes explica que al ser Payemingo un personaje pro norteamericano, se le concedió una medalla de reconocimiento.

${ }_{39}$ Para los chactás, vid. POWELL, J. W. Indian Linguistic, families of America, North of México. Report of the Burean of Ethnology to the Secretary of the Smithsonian Institution. 1891, pp. 1- 142.
} 
segundo lugar, que la obtención de la firma fue ocasionada con engaño, al parecer los compromisarios americanos embriagaron a los nativos para hacerles poner una marca en un papel ${ }^{40}$. Otro de los agentes al servicio español, aunque también lo estuvo del norteamericano, como ya hemos citado, fue Alexander McGuillivray. En la misma época que Thomas Washington estaba tramando en Georgia y Carolina la ocupación de nuevos territorios en la zona española, McGuillivray comunicó, desde la misma Charleston, a Miró, en Nueva Orleans, que si bien el enorme torrente de migración americana estaba contenida en el este, lo cierto era que en el oeste se estaban perfilando nuevos proyectos para crear establecimientos. El agente informó $^{41}$ que los georgianos habían concedido a diferentes colonos entorno a los 16 millones de acres bajo el auspicio de tres grandes compañías ${ }^{42}$ : la de Virginia (encabezada por gobernador Henry); la de Carolina del Sur (cuyo máximo ponente era el coronel William Moultrie) y la de Georgia (impulsada por el coronel Washington). Ante la posibilidad de un conflicto abierto, el gobernador de La Habana, Luis de las Casas, no dudó en informar que la mejor solución de todas pasaba por una negociación con los Estados Unidos, y cederles todo el territorio del margen izquierdo del río Mississippi, concretamente desde el río Ohio hasta los treinta y un grados de latitud norte ${ }^{43}$. Sin embargo, también es cierto que el gobernador dudaba de las intenciones de los vecinos norteños, a los que calificaba como "incómodos, exigidores, altivos y con el tiempo peligrosos", pues según su parecer no buscaban otra cosa que la libre navegación por el Mississippi, a la que se oponía rotundamente. Pero el gobernador también se quejó muy a menudo de la carencia de mapas que delimitasen claramente los territorios de los españoles, los nativos y los norteamericanos. Sobre el proyecto de las compañías existe un informe, de Santiago O'Fallon ${ }^{44}$, agente general de la compañía de Carolina del Sur, datado en Lexington el 16 de julio de 1790, a Esteban Miró que detalla la planificación de la misma, pero que también ofrece una posibilidad a las autoridades españolas. En ese relato especificó que los promotores americanos tenían una

GALLOWAY, Patricia. Choctaw Genesis 1500-1700. Lincoln: University of Nebraska Press, 1995; O'BRIEN, Greg. Choctaws in a Revolutionary Age, 1750-1830. Lincoln: University of Nebraska Press, 2002.

${ }^{40} \mathrm{AHN}$, Estado, Leg. 3898, "El barón de Carondelet al conde de Aranda, 1792”, fol. 29.

41 Ibídem, fol. 25 y ss.

42 BL, LEDWARD, K. H. (ed.). Journal, January 1769: Volume 76. In: Journals of the Board of Trade and Plantations: Volume 13, January 1768-December 1775. London, 1937, pp. 89-95, cita un memorial de diversos habitantes de Gran Bretaña, Virginia y Maryland ante el Rey, (cincuenta peticionarios en total) para que las autoridades británicas autorizasen su asociación, con el nombre de la Compañía de Misisipi, y permitiera ocupar dos millones quinientos mil acres de tierra, entre el 38 ${ }^{\circ}$ y el $42^{\circ}$ grado de latitud norte.

${ }^{43}$ AGS, Estado, SGU, Leg. 7245, 32, fol. 35 "Carta reservada núm. 9, 20 de noviembre de 1790". El 14 de Agosto de 1795 se reunió de nuevo el Consejo de Estado que se inclinó por conceder la navegación por el Mississippi y establecer la frontera en el paralelo 31N N". AHN, Es, 28079 "Tratado de San Lorenzo de Amistad, Comercio y Navegación entre España y los Estados Unidos de América, firmado el 27 de octubre de 1795." El tratado, conocido como tratado de amistad, límites y navegación o tratado Pinckney, fue firmado por España, representado por Godoy, y los Estados Unidos, representados por Thomas Pinckney, para definir las fronteras y regular los derechos de navegación en el río Mississippi.

44 PARISH, J. C. The Intrigues of Doctor James O'Fallon. The Mississippi Valley Historical Review. 1930, n. 17-2, pp. 230-263. En AGS, SGU, Leg. 6928, 2, las autoridades españolas de Luisiana retrataron a O'Fallon "vive en la casa de su suegro, Mr. Clark, cerca de Louisville...no dudo que se abandonará a las mayores vilezas, engaños, falsedades y toda suerte de traiciones". 
amplia red de contactos y alianzas en el gobierno, pero que no creían que los españoles estuvieran interesados en el poblamiento de la cuenca del Yasoo ${ }^{45}$, un afluente del Mississippi.

La colonia prevista en la cuenca del Mississippi debía buscar colonos en las dos Carolinas y Georgia, especialmente en la ciudad de Franklin. Se necesitaban entre 3000 y 5000 hombres, "bien organizados, desembarazados de sus mujeres e hijos...con armas, municiones de boca y guerra, y artillería gruesa, deben bajar por el Tennessee, Ohio y Mississippi y situarse en el paraje determinado, cerca del Yasoo, al norte de Natchez, en el límite divisorio de las naciones Chactás y Chickasaw $^{\text {,46 }}$. Planes que se estaban desarrollando con mucho secreto y prevención. El plan de establecimiento colonial, de defensa militar, era el siguiente. Se debían formar compañías de 100 hombres, limítrofes unas con otras. Estas, a su vez formarían batallones y brigadas. Debería constituirse una compañía de caballería junto a unos cuatrocientos hombres de infantería. Se concederían 200 acres de terreno a cada soldado; 300 a cada subteniente o alférez; 400 a cada teniente; 500 a los capitanes; 550 a un sargento mayor y 600 a un coronel. El barón de Carondelet, en una carta que remitió a la Secretaría de Estado, afirmó que "No puedo dexar de hacer presente a V.E. con esta ocasión la falta total de defensa y fuerzas que he hallado en estas provincias y temo que no estoy en el caso de no poder resistir a una invasión repentina de cinco a seis mil americanos bien armados que intentaren baxar por el río hasta esta capital” ${ }^{\text {47 }}$.

Para O'Fallon, estos planes abrían dos posibilidades: negarse, lo que implicaba la hostilidad con los españoles, y la correspondiente ayuda del Congreso de los Estados Unidos a sus colonos, o bien intentar cambiar la dirección del poblamiento en favor de España, con lo cual "la corona tendrá un valioso aliado con estos americanos independientes" ${ }^{\prime 48}$. Para ello se necesitaría formar una compañía propia, que se separaría de la unión, juraría lealtad a España y se convertía en una barrera contra la expansión. Todo ello a cambio de ciertos privilegios, protección y comercio. Las posibilidades comerciales del extenso territorio de Luisiana eran percibidas por muchas sociedades mercantiles, desde la irrupción de agentes ingleses, que intentaron acaparar el mercado de las pieles, hasta las peticiones del virrey conde de Revilla Gigedo, reclamando la autorización de libre comunicación para contratar entre Texas y Luisiana ${ }^{49}$. Con esas intenciones le nombró comisionado para negociar secretamente una solución ${ }^{50}$. Esta planificación llegó rápidamente a las autoridades militares españolas de La Habana, y Luis de las Casas envió una serie

\footnotetext{
${ }^{45}$ CARSON, James T. Horses and the Economy and Culture of the Choctaw Indians, 1690-1840. Ethnohistory. 1995, pp. 495-513, analiza las relaciones de agentes indios y la economía de las naciones de la confluencia del Yasoo. Por su parte, WHITAKER, Arthur P. The South Carolina Yazoo Company. The Mississippi Valley Historical Review. 1929, vol. 16, n. 3, pp. 383-394, explica como la compañía del Yazoo de Carolina es un magnífico ejemplo de la política centrífuga de la tenencia de tierras y de la especulación sobre las mismas. Sobre la cartografía norteamericana del Yazoo, vid. LOC, Mississippi River--Maps, Manuscript, "Map of the Mississippi River from the mouth of Yazoo River to the southern part of Louisiana, 1774".

${ }^{46}$ AGS, Estado, SGU, Leg. 7245, 32, "Pobladores y comercio...", fol.126.

${ }^{47}$ AHN Estado, 3898, Exp. 5, "Cartas del barón de Carondelet, 1792", fol. 7.

${ }^{48}$ Ibídem, fol. 129.

${ }^{49}$ AGI, Estado, 21, N 60, "Sobre comunicación libre y comercio entre Luisiana y Texas, 1793".

${ }^{50}$ Ibídem, fol. 126 vto.
} 
de órdenes a Esteban Miró, el 20 de noviembre de 1790, con unas contundentes palabras que si "se intentase por la violencia usurpar ni una pulgada de terreno....deberá usted, si llega el caso, defenderla con las armas en la mano..." Sin embargo, debía prevalecer el sentido común ante esas pretensiones, aún no clarificadas del todo. Por ello, las autoridades militares de Nueva Orleans advirtieron que si, efectivamente, los colonos se asentaban en el norte se debería evitar "...venir a las manos con ellos para no comprometer a nuestra corte en empeños que en todos tiempos serían de alguna gravedad con consideración que se llegara a combatir con gentes numerosas, aguerridas en ese tipo de peleas en bosques..."52. En ese sentido, el gobernador de La Habana, Luis de las Casas, recomendó a las autoridades militares de Luisiana y a todas las fortificaciones de la misma que estuvieran prevenidos contra cualquier irrupción de hombres de Kentucky. Incluso no descartó iniciar una política de poblamiento para introducir colonos españoles en la zona de Natchez ${ }^{53}$.

Las autoridades hispanas de Luisiana, ante la amenaza colonial que venía de los Estados Unidos, reaccionaron rápidamente, remitiendo una expedición al paraje conocido como Nogales para la construcción de un fuerte. A ese efecto enviaron una galera y una lancha cañonera para localizar un lugar apropiado e iniciar los trabajos de fortificación. Dicha expedición estaba formada por un sargento, once soldados, un patrón, seis marineros y un técnico holandés en fortificaciones al mando de Manuel Gayoso. El fuerte estaría dotado con la artillería que portaban las embarcaciones, a saber cuatro cañones de seis libras, dos de cuatro, dos de dos y ocho pedreros de media libra. La expedición, en un primer momento, quería construirlo en un paraje denominado "el Vergel", pero había demasiados cañaverales y estaba dominado por otras alturas. De esta forma lo trasladaron más al norte, a poca distancia, sobre una colina que domina todo el paisaje. Además, muy cerca de ese nuevo lugar existía un pequeño puertecillo natural capaz de recibir dos galeras. Pero no sería la única construcción que se realizaría, también se procedió a reconstruir el fuerte de Arkansas con ayuda de los indios osages ${ }^{54}$. En ese mismo sentido, los cherokees, también solicitaron a las autoridades españolas de Nueva Orleans que reactivasen dos fuertes abandonados que habían construido los franceses en la zona del Tombecbe ${ }^{55}$ y del río Tenesse ${ }^{56}$.

\footnotetext{
51 Ibídem, fol. 248.

52 lbídem, fol. 251 vto.

${ }^{53}$ AGI, Estado, 9, N3, "Gobernador Habana sobre Kentucky y estados inmediatos, 1791".

54 NASATIR, Abraham. The Imperial Osages: Spanish-Indian Diplomacy in the Mississippi Valley. Norman: University of Oklahoma Press, 1983. Por su parte, GONZÁLEZ LÓPEZ-BRIONES, Carmen. Reacciones diferentes ante una Política Similar. Op. Cit., pp. 119-130, explica la respuesta extremadamente violenta que tuvieron los osages para los cazadores que se internaban en su territorio. Respuesta que dieron tanto bajo el mandato francés como español de Luisiana. Conducta que mantuvieron pese a las amenazas de cortarles el comercio.

${ }^{55}$ Existe una abundante cartografía de los fuertes franceses y españoles en el territorio de Luisiana, entre los mejores destacaríamos los conservados en los Archives Nationales d'Outre Mer, concretamente en el Atlas Moureau de Saint Méry, como el de Tombecbé. Este fuerte fue construido por los franceses en 1720 En la confluencia de los ríos Tombigbee y Alabama. Si bien en un principio se erigió para evitar una penetración británica, en 1736 se refortificó y fue la base de penetración gala en la guerra contra los Chicachas.

${ }^{56}$ AGI, Estado, 9, N 27, "El gobernador de La Habana sobre la edificación de dos fuertes, 1794".
} 
En 1791 John Williams envió una carta a Esteban Miró narrándole el viaje que había realizado a Kentucky. La misiva incorporaba información sobre la construcción de la fortificación española de Nogales. Williams se entrevistó con el general George Clark y O'Fallon, que acto seguido emprendieron un viaje exploratorio. En ese sentido cabe señalar que el general Clark también tuvo intenciones de ocupar Luisiana. Ante esa posibilidad, la corona española dio instrucciones al capitán general de ese territorio para que facilitase armas de fuego a los creeks con el fin de oponerse a esa invasión ${ }^{5}$.

Al cabo de pocos días Williams informó de una entrevista que había mantenido en las "caídas del Ohio"58. En ella se habló largo y tendido, como queda reflejado, de la compañía de colonos que se estaba formando para poblar el territorio pero, sobre todo, de la división de opiniones que existía entre ellos sobre la posibilidad de que los españoles fortificaran Nogales. Para unos, ese establecimiento entorpecería el comercio; para otros, no implicaba cambio alguno ${ }^{59}$. Fortificación que, recordémoslo, había sido autorizada por el conde de Floridablanca, quien le dio el visto bueno ${ }^{60}$. Ese mismo año, concretamente el 15 de enero de 1791, O'Fallon remitió a Esteban Miró una carta desde Kentucky en la que le informaba que había regresado de Cumberland y Franklin, donde los deseos del nuevo poblamiento estaban tremendamente difundidos, añadiendo que "los notables más acaudalados están muy entusiasmados" ${ }^{\prime \prime}$. También afirmó que los colonos estaban preparados, que irían acompañados de una dotación militar y de milicias compuestos por caballería, infantería y artillería. Para realizar dicho viaje, McGuillivray les había concedido un salvoconducto para cruzar las tierras de los Creek. O'Fallon, como en otras ocasiones, advirtió que una respuesta militar española podía precipitar una guerra con los Estados Unidos ${ }^{62}$. Pero O'Fallon no dejaba de ser un aventurero más, tal y como lo evidencia la documentación norteamericana ${ }^{63}$, que también se interesó por invadir el territorio español, cuestión que fue vetada por Washington, tal y como lo comunicó Wilkinson en una carta reservada a las autoridades de Nueva Orleans $^{64}$.

La coyuntura de presión de colonos, la existencia de un conjunto muy variado y heterogéneo de indígenas que poblaban el valle del Mississippi ${ }^{65}$, los intereses político-económicos de la joven república norteamericana, y la irrupción británica en el golfo de México no fueron los únicos problemas a los que tuvo que enfrentarse España en el territorio de Luisiana. A ello se le tuvo que sumar un hecho

\footnotetext{
${ }^{57}$ AGI, Estado, 58, N 158, "Problemas en Luisiana y Florida, 1795".

${ }^{58}$ Washington percibió la extremada importancia que tenía la comunicación fluvial para los jóvenes Estados Unidos, vid. la correspondencia entre el general George Clark y George Washington en LOC, George Washington Papers, General Correspondence.

${ }^{59}$ AGI, Estado, 9, N 16, "Gobernador Luisiana sobre el paraje llamado Walnut Hills, 1791", fol. 4.

${ }^{60}$ Ibídem, fol. 11.

61 Ibídem, fol. 29

62 Ibídem, fol. 37.

${ }^{63}$ LOC, The Thomas Jefferson Papers at the Library of Congress, General Correspondence, Kentucky District Attorney, March 22, 1791.

${ }^{64}$ AGI, Estado, 9, N 10, "Sobre el proyecto de don Santiago O'Fallon contra Luisiana, 1792".

${ }^{65}$ ADAIR, James. The History of the American Indians: Particularly Those Nations Adjoining to the Mississippi, East and West Florida, Georgia, South and North Carolina, and Virginia. Cambridge: Cambridge University Press, 2013.
} 
transcendental: las consecuencias de la revolución francesa ${ }^{66}$ entre los habitantes de cultura gala en Luisiana, y la emergencia de las ideas que subyacían en la nueva filosofía política en toda América Latina. Por ese mismo motivo las autoridades comunicaron rápidamente a la corte "la rapidez que van tomando en ella la nueva máxima de libertad que ha adoptado la Francia"67, recordando que hasta 1763 Luisiana fue territorio francés ${ }^{68}$ y sus colonos continuaban con el carácter y costumbres de su primitiva nación, como lo evidencia la detención de comerciantes franceses Jean Bujac ${ }^{69}$ y sus compañeros asentados en esa área, calificados como "peligrosos" por la defensa que realizaban de la independencia y la libertad ${ }^{70}$. Por todo ello era necesario dotar de más hombres y recursos, dado que era el punto más expuesto $^{71}$. Petición que no surtió demasiado efecto por cuanto el gobernador de La Habana, Luis de las Casas, remitió únicamente un batallón para combatir esa "rápida expansión de las ideas revolucionarias". En todo caso, también se intentó paliar con un bando promulgado por el barón de Carondelet, el 15 de febrero de 1793 en Nueva Orleans, amenazando con una severa represión. Las cartas reservadas sobre movimientos sediciosos de carácter republicano realizados por colonos franceses en Luisiana fueron, a lo largo de 1793 y 1794, muy comunes. Esta situación, junto a los intereses norteamericanos en toda la cuenca del Mississippi, se convertía en un serio problema, y más teniendo en cuenta que en Boston y Filadelfia se imprimió, y se envió a los territorios hispanos de toda América ${ }^{72}$, la declaración de los derechos del hombre y del ciudadano, promulgado en Francia ${ }^{73}$. En la misma línea que el anterior también se imprimió otro título, se trataba de "Desengaño del Hombre"74. Esta última obra, de James Philip Puglia, fue editada en Filadelfia, concretamente en la imprenta de Carey y Lea, de la calle Chesnut. Se trataba de un duro alegato, impulsado por Thomas Jefferson, contra el despotismo. Ideas, estas, que alcanzaron todos los territorios de la América hispana, como lo evidencia la detención, nada más ni nada menos, que del cocinero del virrey conde de Revilla Gigedo $^{75}$. Las autoridades virreinales remitieron un amplio informe a la corona sobre los grandes peligros que suponía la llegada continua de franceses a los Estados

\footnotetext{
${ }^{66}$ GASPAR, D. B. y GEGGUS, D. P. (eds.). A Turbulent Time: The French Revolution and the Greater Caribbean. Bloomington: Indiana University Press, 1997.

${ }^{67}$ AGI, Estado, 14, N 7, "Sobre refuerzo de tropas para Nueva Orleans, 1793", fol. 2.

${ }^{68}$ LE CLĖRE, A. (ed.). Notice sur l'état actuel de la mission de la Louisiane. Paris: Impr. de A. Le Clère, 1820. Relaciona "la inmensidad del territorio del Missouri".

${ }^{69}$ AGI, Estado, 14, N7, "Sobre el refuerzo de tropas para Nueva Orleans, 1793", se explicita como, “...y me ha remitido a un Bujeac, principal cómplice de la fermentación", fol. 2.

${ }^{70}$ AHN, Estado, Leg. 3898, "El barón de Carondelet al conde de Aranda, 1792", fol. 3.

${ }^{71}$ Ibídem, fol. 4.

72 PIETSCHMANN, H. Revolución y Contrarrevolución en el México de las reformas borbónicas Ideas protoliberales y liberales entre los burócratas ilustrados novohispanos (1780-1794). Caravelle. 1990, n. 54, pp. 21-35.

${ }^{73}$ En la Biblioteca Nacional de Francia, se hallan algunos documentos de las logias masónicas de Nueva Orleans, Département des Manuscrits, FM2 (561), Nouvelle-Orléans (Louisiane), Correspondance des loges avec le Grand Orient de France. Loges de l'étranger. Loges des ÉtatsUnis. La Nouvelle-Orléans (Louisiane). Documentos datados entre 1767 y 1856 que recogen el sentir de los descendientes de los colonos franceses ante la situación internacional. En este sentido, y para comprender la importancia de este tema, cabe recordar que uno de los agentes más activos, McGuillivray, en los últimos años de su vida se mudó a Pensacola e ingresó en su logia masónica.

${ }^{74} \mathrm{AGI}$, Estado, 22, N 36, "Carta reservada del virrey de Nueva España, marqués de Branciforte al duque de Alcudia, 1794".

${ }^{75}$ AGI, Estado, 22, N 35, "Branciforte sobre providencias que tomó con sediciosos, 1794".
} 
Unidos, la protección de su gobierno de los mismos, y la publicación de ideas tremendamente perjudiciales para España y sus posesiones. En este largo documento, se deja constancia del temor del virrey de Nueva España de una posible ocupación norteamericana de Nueva Orleans y, avanzaba tempranamente, la posibilidad que si los Estados Unidos accedieran a la libre navegación por el Mississippi, no tardarían en intentar ocupar Texas. Otra de las medidas establecidas fue la de enviar compañías de soldados a las provincias de Coahuila y Texas para registrar los poblados nativos más inclinados al gobierno norteamericano en busca del libro "Desengaño del hombre",76.

La demarcación de límites, si bien tranquilizó momentáneamente a las autoridades de ambos países, no alejó por completo el peligro. En 1797 el comandante general de las Provincias Internas, Pedro de Nava, temía una invasión norteamericana en Luisiana, y a tal efecto se lo comunicó a Godoy. Los informes fueron enviados al gobernador por el alférez José Guadiana destinado a la guarnición de Nacogdoches, el cual aseguró tener constancia de un posible ataque $^{77}$. En todo caso esa situación, de temor y peligro, tenía una contradicción. La corona eliminó la dotación presupuestaria y los pagos a determinados agentes que tenía en la zona, concretamente a los intérpretes nativos de la confederación, los de San Fernando de las Barrancas, y los de Nogales, Natchez y San Esteban y que solo ascendían a 6.600 pesos fuertes al año ${ }^{78}$.

\section{Conclusiones}

Entre 1790 y 1797 Luisiana vivió momentos de intranquilidad por parte de sus autoridades cuando aventureros, empresarios y militares norteamericanos apreciaron el potencial de todo ese territorio, percibiéndolo como una región libre y vacua, a pesar de existir numerosas naciones indias y pese al supuesto control que España tenía del mismo. Los intentos desestabilizadores, los proyectos de colonización y los planes de invasión se fueron sucediendo en una escalada que parecía que no tendría fin. Que acabaría en una verdadera guerra entre la corona de España y la joven república de los Estados Unidos. En esa dinámica, agentes y agentes dobles intervinieron facilitando información, y también desinformación, a las autoridades hispanas de Nueva Orleans. Las continuas cartas emitidas por esos agentes dobles fomentaron una verdadera convicción de que la disputa colonial acabaría en guerra abierta. Ello condujo a una nueva dinámica que acabó en una política de creación de fortificaciones, y actualización de las ya existentes. Fortificaciones que, dada la precariedad económica, humana y militar, española, se complementaron con pactos con los nativos, a los efectos de tener un aliado para poder frenar una presión de colonos que sabían que sería imparable. En ese juego estratégico que hemos señalado, de agentes y agentes dobles, hallamos a personajes que tuvieron un gran peso en el diseño de la política norteamericana en la región, y en la creación de un verdadero estado de ánimo, tanto en Nueva Orleans como en Madrid, que posibilitaría una inversión en la defensa colonial, cediendo

\footnotetext{
${ }^{76}$ AGS, SGU, Legajo 7023, 16, "Medidas para evitar la introducción del libro Desengaño del Hombre, 1794".

${ }_{77}^{7 G I}$, Estado, 37, N 23, "Hostilidades contra la Luisiana, 1797".

${ }^{78}$ AGI, Estado, 1, N 98 C, "El Intendente de Luisiana remite relación de empleados, 1797".
} 
territorio y navegación a los Estados Unidos. Entre los principales actores de la inteligencia norteamericana, hallamos las labores de McGuillivray (que siempre actuó o bien persiguiendo el beneficio propio o para brindar a los creek de mayores posibilidades defensivas y buscando réditos de las autoridades de Washington); las de James Wilkinson, que tuvo una labor decisiva de información, pero también de absoluta desinformación, al gobernador militar de Nueva Orleans; o los de otro aventurero, O'Fallon, que no se rendía a los intentos de convertirse en un gran terrateniente en la cuenca del río Yasoo y que no dudó en informar al gobernador español de Luisiana de planes militares de conquista por parte de colonos americanos.

La posibilidad que las grandes apetencias territoriales de los distintos estados limítrofes con Luisiana (Kentucky, Georgia y las dos Carolinas), impulsadas y exageradas por esos agentes de inteligencia, acabaron por convencer a la Corte hispana de la necesidad no solo de firmar tratados con las naciones indias de la cuenca del Mississippi (tratado de Nogales). A ello se le sumó el intento de frenar a los Estados Unidos mediante la cesión de un amplio territorio que abarcaba un área enorme, situada al norte de Luisiana, que llegaba hasta la mitad del río Mississippi. Los norteamericanos convencidos de aquella línea expansiva advertida por George Washington, que los ríos eran verdaderos motores económicos para todos los estados, se ejecutó perfectamente, puesto que lograron la libre navegación no solo por el Mississippi, sino también por los ríos que desembocaban en el mismo. Esa cesión alejó el peligro momentáneo y puso los pilares de la construcción de un nuevo estado tremendamente poderoso, abriendo las puertas del oeste a los colonos norteamericanos.

\section{Fuentes}

Archivo Histórico Nacional (AHN)

Archivo General de Simancas (AGS)

Archivo General de Indias (AGI)

Library of Congress (LOC)

British Library $(\mathrm{BL})$

Archives Nationales d'Outre Mer (ANOM)

Bibliothèque Nationale de France (BNF)

\section{Bibliografía}

ACOSTA, Antonio. La población de Luisiana española [1763-1803]. Madrid: Ministerio de Asuntos Exteriores, 1979.

ADAIR, James. The History of the American Indians: Particularly Those Nations Adjoining to the Mississippi, East and West Florida, Georgia, South and North Carolina, and Virginia. Cambridge: Cambridge University Press, 2013.

ARMILLAS VICENTE, José Antonio. El Mississippi, frontera de España. España y los Estados Unidos ante el tratado de San Lorenzo. Zaragoza: Institución "Fernando el Católico" (C.S.I.C.); Departamento de Historia Moderna,1977. 
CARSON,James T. Horses and the Economy and Culture of the Choctaw Indians, 1690-1840. Ethnohistory. 1995, pp. 495-513.

DINN, Gilbert. La defensa de la Luisiana Española en sus primeros años. Madrid: Servicio Histórico Militar, 1978.

DINN, Gilbert y NASATIR, Abraham. The Imperial Osages: A Study of Spanish Indian Diplomacy in the Mississippi Valley. Norman: University of Oklahoma Press, 1983.

ETHRIDGE, Robbie. Creek country: the Creek Indians and their world. Chapel Hill: UNC Press Books, 2004.

FIEHRER, Thomas. The baron de Carondelet as agent of Bourbon reform: a study of spanish colonial administration in the years of the French revolution. N. O.: Tulane University, 1977.

GALLOWAY, Patricia. Choctaw Genesis 1500-1700. Lincoln: University of Nebraska Press, 1995.

GONZÁLEZ LÓPEZ-BRIONES, Carmen. Reacciones diferentes ante una Política Similar: Los indios Osages y los Quapaws ante la política comercial francoespañola en la Luisiana durante el siglo XVIII. Anales del Museo de América, 1995, pp. 119-130.

HILTON, Sylvia L. Movilidad y expansión en la construcción política de los Estados Unidos: "estos errantes colonos" en las fronteras españolas del Misisipí (17761803). Revista complutense de historia de América. 2002, vol. 28, pp. 63-96.

HOLMES, Jack. Louisiana in 1795 the Earliest Extant Issue of the "Moniteur De La Louisiane". Louisiana History. 1966, pp. 133-151.

JACOBS, Wilbur (ed.). The Appalachian Indian Frontier: The Edmond Atkin Report and Plan of 1755. Lincoln: University of Nebraska Press, 1967.

MONTERO, José. Españoles en Nueva Orleans y Luisiana. Madrid: Ediciones Cultura Hispánica del Centro Iberoamericano de Cooperación, 1979.

NASATIR, Abraham. The Imperial Osages: Spanish-Indian Diplomacy in the Mississippi Valley. Norman: University of Oklahoma Press, 1983.

O'BRIEN, Greg. Choctaws in a Revolutionary Age, 1750-1830, Lincoln: University of Nebraska Press, 2002.

PARISH, J. C. The Intrigues of Doctor James O'Fallon. The Mississippi Valley Historical Review. 1930, n. 17-2, pp. 230-263.

POWELL, J. W. Indian Linguistic, families of America, North of México. Report of the 
Burean of Ethnology to the Secretary of the Smithsonian Institution. 1891, pp. 1142.

RODRÍGUEZ CASADO, Vicente. Primeros años de dominación española en la Luisiana. Madrid: CSIC, 1942.

WEBER, David J. Borbones y Bárbaros. Centro y periferia en la reformulación en la política de España hacia los indígenas no sometidos. Anuario Instituto Estudios Histórico Sociales. 1998, n. 13, pp. 147-171.

WHITAKER, Arthur P. The South Carolina Yazoo Company. The Mississippi Valley Historical Review. 1929, vol. 16, n. 3, pp. 383-394. 